\title{
The Impact of Supply Chain and Business Process Managements on Firm Performance: The Mediating Effect of Competitive Advantage: Part II Testing Hypotheses
}

\author{
Byeong-Yun Chang ${ }^{1}$, Yabibal A. Abate ${ }^{2}$ and Byungjoo Park ${ }^{3 *}$ \\ ${ }^{1,2}$ School of Business Administration, Ajou University, Suwon, (South) Korea \\ ${ }^{3}$ Department of Multimedia Engineering, Hannam University, Daejeon, (South) \\ Korea \\ 'bychang@ajou.ac.kr, ${ }^{3}$ bjpark@khu.ac.kr
}

\begin{abstract}
In today's fierce competition situation in business world, achieving business competence is an essential part of firms' survival and sustainability. This paper discusses how supply chain and business process managements are related in in building firms' competitive advantage and for better performance outcomes. In Chang and Park (2017), Supply chain and business process management practice antecedents were identified based on studying prier literature. They presented an integrated framework of SCM and BPM and constructed 6 research hypotheses. In this paper, we tested them using a sample of 74 Tanzanian firms. Partial least square based structural equation modeling (PLS$S E M)$ method was used to test the hypotheses. The empirical test results indicate that both SCM and BPM are essential practices for the improvement of firms' overall performance measures. Firms' competitive advantage was found to be a significant mediator between these business practices and organizational performance indicators. Future researches can extend the findings of this study to develop advanced frameworks and to investigate the case of other countries.
\end{abstract}

Keywords: SCM, BPM, competitive advantage, organizational performance

\section{Introduction}

Today's fierce competition situation in business world have already required organizations to improve not only their internal business process, but their entire supply chain to be made competitive (Li et al., 2005; Youn, 2013; Li et al., 2006; Agus, 2011, Chang and Park 2017). Therefore, the understanding and practice of supply chain management (SCM) and business process management (BPM) across their own companies necessary for any company, regardless of the nature of their business, to remain competitive and profitable.

SCM encompasses materials and supplies management from the supply of basic raw materials to final product (and possible recycling and re-use). It focuses on how firms utilize their suppliers' processes, technology and capability to enhance competitive advantage. It is a management philosophy that extends traditional intra-enterprise activities by bringing trading partners together with the common goal of optimization and efficiency (Tan et al., 1998). It is an integrative approach to dealing with the planning and control of the materials flow from suppliers to end-users (Tan, 2001). A network of firms interacting to deliver product or service to the end customer, linking flows from raw material supply to final delivery (Ellram, 1990). The council of logistics management (CLM) defined SCM as a systemic and strategic coordination of traditional business practices across all those business functions within a particular organization and across entities involved in the entire supply chain for the purpose of long term improvement of individual organizations and the supply chain as a whole (CLM, 2000).

*Byungjoo Park is the corresponding author. 
As mentioned SCM in Chang and Park 2017, BPM is defined as all efforts in an organization to analyze, and continually improve all activities and operations of the organization (Zairi, 1997; Trkman, 2010; Skrinjar and Trkman, 2013). In order to survive in the ever changing business environment, companies must implement best management practice principles, strategies and technologies (Hung, 2006; Carpinetti et al., 2003). BPM is regarded as best practice management principle that helps companies to build and sustain their competitive advantage in the near and far futures.

Many researchers and business organizations still tend to see SCM as integrated logistics management or as a synonymous for supplier management. Some business organizations may realize the importance of SCM yet they don't know what constitutes a comprehensive SCM practices. On the other hand, some see BPM as just simply IT functions of the business organization. For many others it is used only to describe the process oriented philosophy in managing the activities of the organization. In Chang and Park 2017 we have conceptualized the common practices of SCM and BPM and developed 6 research hypotheses.

Following the Chang and Park 2017, this study is therefore to empirically test a framework identifying the relationship between BPM and SCM and their impact on organizational performance with a mediating effect of organizational competitiveness. We try to answer the following specific questions in particular. How and to what extent SCM improves firm's financial and operational performance through improving their competitive advantage? How and to what extent BPM affects overall organizational performance by helping firms to build their competitive advantage? How and to what extent understanding and practice of BPM will help firms to build a competitive SCM practice?

\section{Research Hypotheses}

In Chang and Park, 2017, they presented an integrated framework of SCM and BPM and 6 research hypotheses. The figure 1 and the followings describe them.

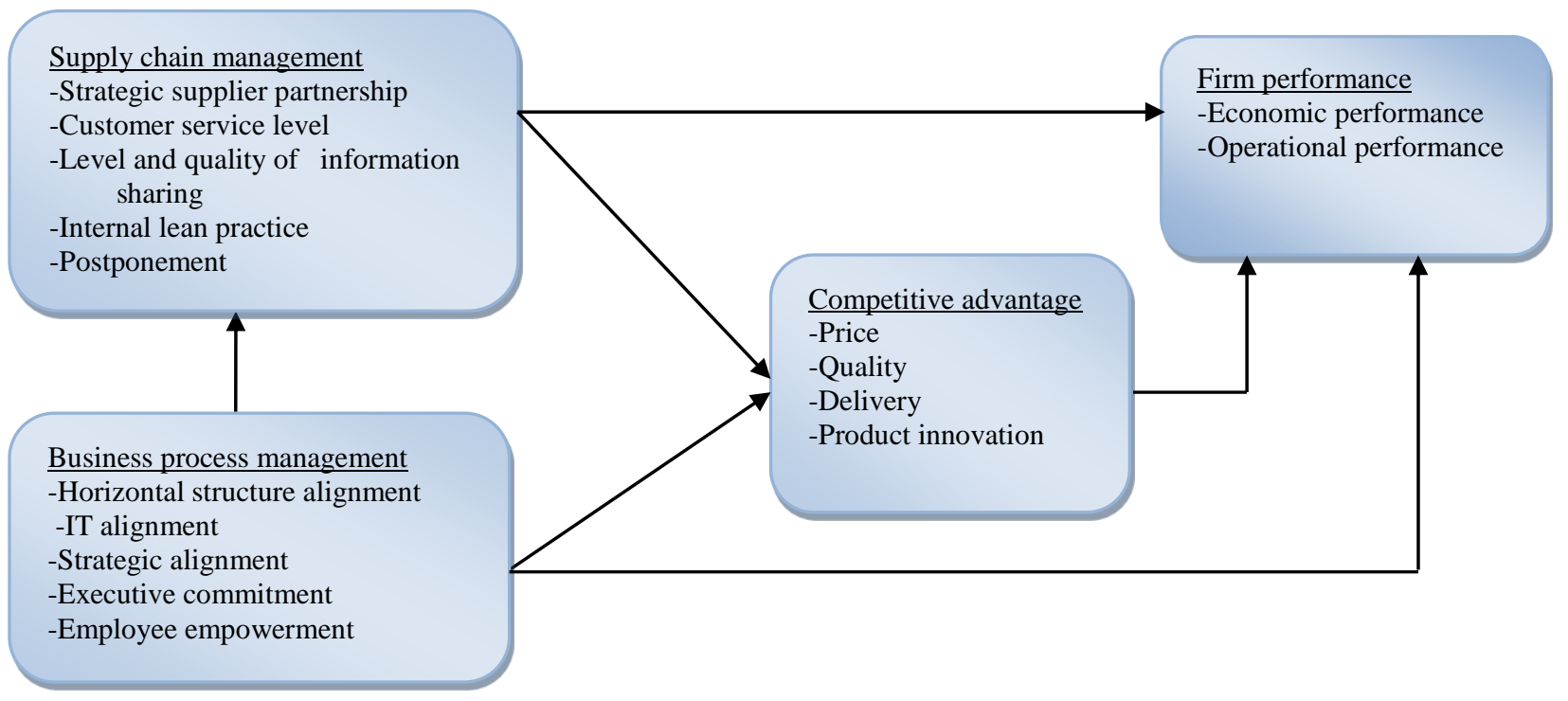

Figure 1. The Conceptual Framework of SCM and BMP (Chang and Park 2017)

H1: Firms with high level of SCM practice will have high level of market, financial and operational performance.

$\mathbf{H}_{2}$ : Firms with high level of SCM practice will have high levels of competitive advantage 
$\mathbf{H}_{3}$ : Firms with high level of BPM practice will have high level of organizational performance.

$\mathbf{H}_{4}$ : Firms with high level of BPM practice will have high level of competitive advantage.

$\mathbf{H}_{5}$ : Firms with higher level of competitive advantage will have high level of organizational performance

H6: $_{6}$ Firms with high level of BPM practice will have a better SCM practice

\section{Research Methods}

\subsection{Survey Administration and Data Collection}

Data for this study was obtained from questionnaire based survey. Questionnaire items have been drown from prior researches after conducting a comprehensive literature review in the field of SCM and BPM. The necessary data to test the hypotheses was collected from a samples of randomly drown 243 firms from a population of more than one thousand private and public healed Tanzanian firms who are registered under the Tanzanian Investment Center (TIC) and are currently engaging mainly in manufacturing and service sectors. We primarily targeted individuals, who are either top level executives or middle level managers in procurement/purchasing, marketing/sales, production/operation management departments. We specifically targeted those groups based on the notion that they have a better knowledge on the concepts of SCM and BPM practices. Data collection was done both online and through paper-and-pencil approach. Among the 234 questionnaires distributed, 87 of them responded within the time frame we set (three weeks) yielding a 37\% response rate. Among those responses 14 of them were incomplete and were disregarded. The remaining 73 valuable responses were used for further analysis.

Among the 73 respondents, $30(41 \%)$ of them were from production/ operations department and the remaining $26 \%$ from marketing/ sales, $19 \%$ from purchasing/ procurement and $14 \%$ from transportation/ logistics/ distribution department. Also, 44 (61\%) of them assume some managerial position and $65(89 \%)$ of them have been working in their position for more than a year. This leads to a conclusion that our respondents have a better understanding of the concepts of BPM and SCM practices. A summary of the demographic data is given in table 3 .

Table 3. Description of Demographic Data

\begin{tabular}{llll}
\hline Variable & Category & $\mathrm{n}$ & $\%$ \\
\hline \multirow{2}{*}{ Firm's industry } & Manufacturing & 16 & $22 \%$ \\
& Service & 33 & $45 \%$ \\
& Others & 23 & $32 \%$ \\
& & & \\
Respondent position & Top level manager & 10 & $14 \%$ \\
& Middle level manager & 11 & $15 \%$ \\
& First line Manager & 23 & $31 \%$ \\
& Others & 29 & $40 \%$ \\
Respondent area of expertise & Production/ operations & 30 & $41 \%$ \\
& Purchasing/ procurement & 14 & $19 \%$ \\
& Transportation/ distribution & 10 & $14 \%$ \\
& Marketing/ sales & 19 & $26 \%$ \\
Respondents experience (years) & For more than 10 years & & $27 \%$ \\
& From 6-10 years & 20 & $19 \%$ \\
& From 1-5 years & 14 & $42 \%$ \\
& Less than a year & 31 & $11 \%$ \\
\hline
\end{tabular}




\subsection{Response and Common Method Biases}

The typical primary concern of a survey method research is that the data collected from the respondents may contain non-response bias which can lead to a sample that is not a true representative of the population (Forza, C. 2002). But, this research did not investigate non-response bias directly because it had no detail information about organizations except the name and address of individual respondents. However, Armstrong and Overton (1977) recommended that late-returned surveys contain the opinion of non-respondents. Based on this assumption, we divide the 73 respondents in to 42 early respondents (those who replied for the first email within 2 weeks) and 31 late respondents (those who replied after follow up email within another 2 weeks). Then we randomly choose 20 variables and conducted an independent t-test between the two groups and there was no statistically significant difference indicating that non-response cannot be a significant concern.

The other similar concern of a survey method is the common method bias (CMB) which refers to variance attributed to the measurement model rather than the constructs. Since data was collected from a single respondent per organization, it is necessary to check for CMB. Harman's single factor method was applied using CFA to in order to confirm the absence of significant CMB problem. According to Podsakoff et al., (2003), a single factor CFA should fit the data well. The AVE by a single factor was found to be $24 \%$, indicating that very less variation of the data is accounted for by a single factor. This suggests that $\mathrm{CMB}$ is not a great concern hence, further analysis are appropriate.

\subsection{Measures}

\subsubsection{SCM}

SCM was treated as a five dimensional factor and measured with a total of 23 items all derived from Li et al., (2006) and Li et al., (2005). (1) Strategic supplier partnership was measured by 5 items, e.g., "We consider our suppliers in our planning activities". (2) Customer service level was measured by five items. (e.g., "We frequently interact with customers to set reliability and responsiveness"). (3) Level and quality of information sharing was also operationalized with five items, including, "The information exchange between our trading partners and us is mostly accurate, complete and timely". (4) Internal lean practice was measured using five items developed by Li et al., (2005) and Agus (2011) (e.g., "Our firm has continuous quality improvement program". (5) Finally, three items were adapted from $\mathrm{Li}$ et al., (2006) to measure postponement (e.g., "We delay final product finishing activities until we receive actual orders").

\subsubsection{BPM}

Like that of SCM, BPM is also considered as a higher order factor comprised of four dimensions. All items were adapted from Hung (2006). (1) Horizontal structure alignment was measured with a total of five items (e.g., "There are no high barriers between our departments"). (2) IT alignment is another dimension of BPM measured by four items (e.g., "We have a well integrated IT system across functional units"). (3) Strategic alignment was assessed using three items such as "Our strategies are developed based on customer needs". (4) Executive commitment another important dimension of BPM was measured by four items (e.g., "[Our] Executive allocates adequate resources to improve core processes". (5) Lastly, employees' empowerment was measured using three items including "Employees' autonomy in decision making at their work is increasing". 


\subsubsection{Competitive Advantage}

The four sub-dimensions of competitive advantage were measured by a total of 15 items adapted from Li et al. (2005) and Li et al., (2006). (1) Price was operationalized through three items (e.g., "We offer a very competitive price"). (2) Quality, also measured using three items, (e.g., "We offer highly reliable products compared to our competitors"), is another important measure of firms' competitiveness. (3) Delivery was measure by three items including "We deliver the needed product on time". (4) Last but not least, product innovation was assessed using four items (e.g., "We respond well to customer demand for new and additional features").

\subsubsection{Organizational Performance}

Firms' performance can be measure through their economic achievement (marketing performance and profitability) as well as their operational effectiveness. (1) Economic performance was measured using six items derived from Li et al., (2006) (e.g., "Our profit margin on sales has been increasing") whereas (2) Operational performance was measured by six items adapted from Kaynak and Hartley (2008) (e.g., "Total inventory turnover has been improved").

\section{Research Results and Discussion}

\subsection{Measurement Validation}

Following Anderson and Gerbing's (1988) recommendation, a two-step approach was used for structural equation model (SEM) analysis. In the first step, measurement model was tested and reliability, convergent validity, and discriminate validity are checked. In assessing the reliability of the constructs, we used both Cronach's alpha and composite reliability approach (Fornell and Larcker, 1981). All the values were well above the threshold (>0.7) with values ranging from 0.7529 to 0.9594 as shown in appendix A.

We used partial list square (PLS) based SEM to test the structural model. We favored PLS-SEM over covariance based SEM (CB-SEM), due to the advantages that the former can bring, such as, (1) it does not require the data to follow normality; (2) can be applied when the researcher has fewer indicators; (3) large number of indicators can be included in the model; (4) it assumes all measured variance (including error) is useful for explanation and prediction of the relationship (Hair, 2011; Afthanorhan, 2013). Since all factors included in this study are second order variables, we used a "reflective - formative" base confirmatory factor analysis (CFA) known as "hierarchical component model" (HCM) in PLS-SEM. HCM helps researchers to reduce number of indicators in SEM besides making the entire model more parsimonious. It is proved to be very essential when constructs are highly correlated which makes the estimation more biased to multicollineariety (Afthanorhan, 2014).

SCM practice was conceptualized as a five dimensional second order factor (SP, CS, QI, LP and PP). Likewise, BPM is also a four dimensional second order construct composed of SA, HA, IA, EC, and EE. Competitive advantage was measured using PR, QL, DL and PI sub-scales. Finally, overall organizational performance consists of EP and OP. We conducted a series of CFA and the appropriateness of second order factor was justified for SCM, BPM, competitive advantage and organizational performance.

Convergent validity was assessed for each sub-scale under each respective higher order factors by examining the standardized factor loadings presented in appendix A. The values suggest that all the items loadings were significant on their posited constructs ranging from 0.7059 to 0.9595 . Also, if the average variance extracted (AVE) for each construct is greater than 0.50, the convergent validity is established (Fornell and Larcker, 1981). The AVE values for each construct were well above the threshold ranging from 0.5895 to 0.8873 (see appendix A). 
Discriminant validity was examined following the method suggested by Fornell and Larcker (1981). The square root of AVE for each constructs along the diagonal was quite greater than the correlations with other constructs. The other way of assessing discriminant validity is to see the cross loadings of items. In this case, all the items were found to be loading higher to the construct it intended to measure than with other constructs. The significance of formative relationship between first and second order constructs were assessed by the weights of each path. As shown in appendix A, all the weights were significant with t-value ranging from 1.9800 to 19.6675 .

\subsection{Testing the Structural Model}

In the second step, the structural model is evaluated. The composite score of second order constructs were used to model the final SEM path structure Figure 2.

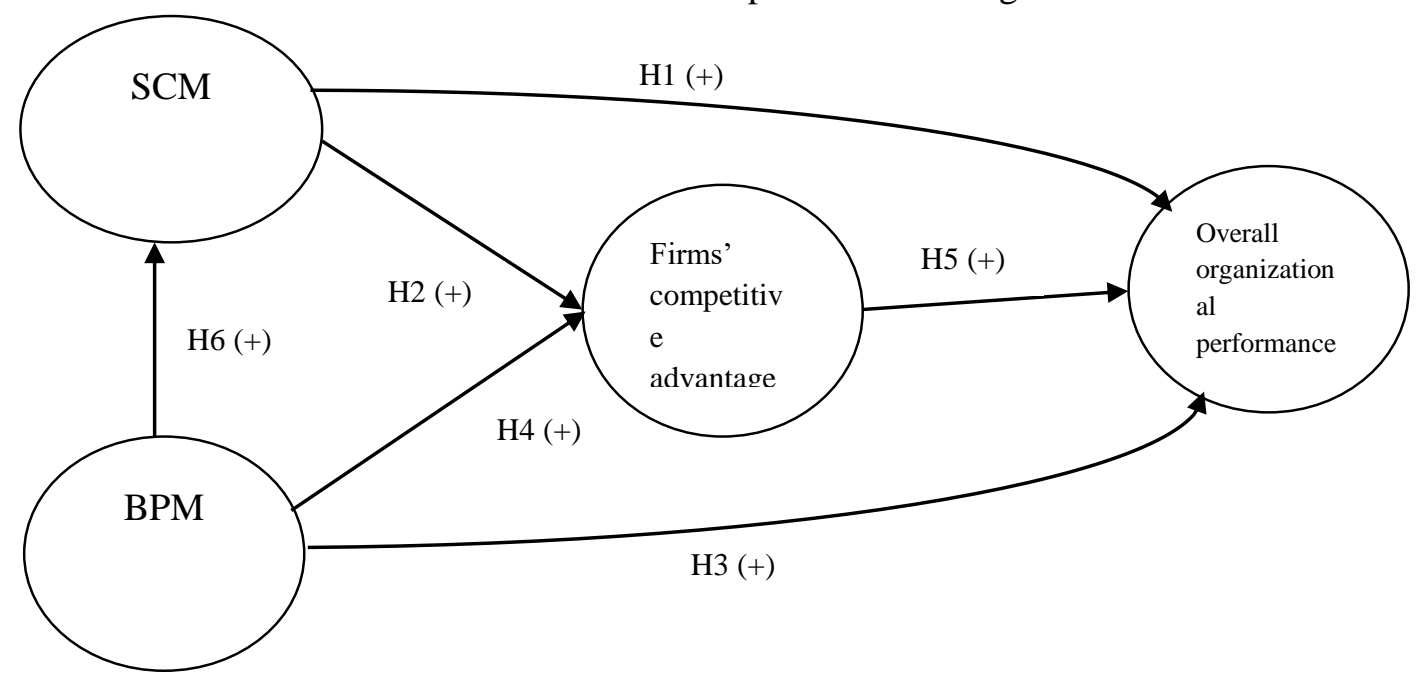

Figure 2. The SEM Final Structure

Multicollinearity was assessed using the variance inflation factor (VIF) method. All the values were found to be below the 5.0 standard (Hair et al., 1998). Therefore, multicollinarity was assessed and there was no multicollinearity problem among the independent variables as shown in table 4. Cohen (1998) suggests that $R^{2}$ value, $>0.26$ as substantial, $>0.13$ as moderate and $>0.02$ as week indication of explained variation of an endogenous variable by a given exogenous indicator. Table 4 presents $\mathrm{R}^{2}$ values of each endogenous variable. All values were well above the "substantial" threshold. Predictive relevance of a reflective endogenous variable can be tested using $\mathrm{Q}^{2}$ and according to Chin (1998), $Q^{2}$ value greater than zero indicates that the respective endogenous variable has a significant predictive relevance. As shown in table 4 , all $\mathrm{Q}^{2}$ values were well above zero hence predictive relevance has been achieved.

The effect size $f^{2}$ is used to assess the impact of a specific predictor (exogenous) variable on an endogenous variable. The value of $f^{2}$ tells what happens to the $\mathrm{R}^{2}$ value of and endogenous variable when a specific predictor variable is omitted from the model. Cohen (1988) suggests that $f^{2}$ value $>0.35$ represents strong effect size while $>0.15$ shows moderate effect size and $>0.02$ indicates a week effect size. In our case, all exogenous variables' effect size value ranges between moderate to strong effect size (Table 4). 
Table 4. Summary of Multicollinearity, $R^{2}$, Predictive Relevance and Effect Size Results $(n=73)$

\begin{tabular}{lccccc}
\hline & & & & \multicolumn{2}{c}{$\mathrm{f}^{2}$} \\
\cline { 5 - 6 } & $\mathrm{VIF}$ & $\mathrm{R}^{2}$ & $\mathrm{Q}^{2}$ & $\mathrm{CA}$ & $\mathrm{OP}$ \\
$\mathrm{BPM}$ & 2.999 & - & - & 0.131597 & - \\
$\mathrm{SCM}$ & 2.325 & 0.6226 & 0.6203 & 0.148105 & - \\
$\mathrm{CA}$ & 3.041 & 0.5699 & 0.5375 & - & 0.442162 \\
$\mathrm{OP}$ & - & 0.7761 & 0.7727 & - & - \\
\hline
\end{tabular}

The hypotheses were tested by assessing the direction, strength, and level of significance of the path coefficients estimated by PLS, using a bootstrap resampling method with 5000 resample following Chin's (1998) suggestion. Sobel's test is used to test the indirect (mediation) effects. Table 5 provides the summary of findings and indirect effects. All the hypotheses were supported at 5\% alpha value except hypothesis one which still can be supported at 0.1 alpha level.

Table 5. Path Coefficients and Significance Level $(n=73)$

\begin{tabular}{llccc}
\hline & & & & \\
Hypothesis & Independent -> dependent variables & Path coefficients & t- statistics & Significance \\
\hline H1(+) & SCM $->$ FP & 0.1678 & $1.6746^{*}$ & P $<0.01$ \\
H2(+) & SCM -> CA & 0.4108 & $2.1786^{* *}$ & P $<0.005$ \\
H3(+) & BPM -> OP & 0.318 & $2.9987^{* * *}$ & P $<0.001$ \\
H4(+) & BPM - C CA & 0.3874 & $2.379^{* *}$ & P $<0.005$ \\
H5(+) & CA -> OP & 0.4798 & $4.043^{* * *}$ & P $<0.001$ \\
H6(+) & BPM $>$ SCM & 0.1678 & $14.2108^{* * *}$ & P $<0.001$ \\
\hline
\end{tabular}

*hypothesis supported at 0.1 alpha level

**hypothesis supported at 0.05 alpha level

***hypothesis supported at 0.001 alpha level

Sobel's test is used in testing the statistical significance of indirect (mediating) relationship between an independent construct and a dependent through a mediator (Daniel, S. Soper, 2004). The test generates t-statistics and p-values for the indirect path. All the mediators were found to be significant (Table 6).

Table 6. Sobel's Test of t- statistics (and p-value) for Indirect Paths $(n=73)$

\begin{tabular}{lccc}
\hline & & \multicolumn{2}{c}{ Path } \\
\cline { 3 - 4 } Latent variable & Linkage & CA & OP \\
\hline BPM & CA & & $2.1297(0.0367)$ \\
& SCM & $2.2290(0.0258)$ & \\
SCM & CA & & $1.967(0.0403)$ \\
\hline
\end{tabular}

\section{Implications and Limitations}

Much of the current theoretical and empirical research on SCM focuses only on downstream or upstream of the supply chain or certain perspectives of SCM. Similarly, while there has been much research on business process modeling techniques and corresponding tools, there has been little empirical research into the success factors of BPM and its impact on firms' competitiveness and overall performance. Moreover, to the best of our knowledge, despite the existing relationship between the practice of SCM and 
BPM, no prior research has investigated the relationship between this two business management practices and their synergistic impact on firms' overall performance. Therefore, this study will contribute for future researches to look into the interrelationship between SCM and BPM in detail and also to investigate the combined effect of the practices of both business principles on organizations competitive advantage and also their impact on firms' economic, operational and other performance measures.

It is important to note that some other contextual factors that are not considered in this study; such as, industry, firm size, the nature (length and complexity) of the supply chain are very important factors for SCM practice. For example, customer service level may be more important for service rendering firms than manufacturing firms. Or, such factor could be very important for firms found at downstream in the supply chain than firms found at upstream. Internal lean practice and postponement are less important for downstream supply chain activities. Hence, these are less important SCM practices for distributors and retailers. Larger firms have the necessary resource to commit for the adoption and implementation of new technologies and innovations, hence, the larger the firm the more likely to adopt BPM practices and applications. Therefore, future studies can target specific industry or group of firms found at the same level in the supply chain network. It might also be important to look in to the group of firms with same size and nature of the business operation separately. Some factors like organizational size can be controlled variables for future studies. Lastly, this study has relied on a sample of 73 Tanzanian firms. Therefore, it is important to consider more firms and more country cases for stronger generalization of findings.

\section{Conclusion}

To conclude, this research investigated the two important business practices of the $21^{\text {st }}$ century firms, i.e., SCM and BPM. We have assessed their synergistic effect in building firms' competitive advantage and ultimately improving their economic and operational performance. Using measurement items adopted from prior studies, a survey was conducted at firm level in the case of Tanzania. After conducting a thorough measurement validation, the proposed structural model was assessed using PLS-SEM method. The empirical analysis results shows that supply chain and business process practices are significant contributors for firms' short and long term economic and operational performance through building organizational competitive advantage.

\section{Appendix A}

Table Summary of measurement scale

\begin{tabular}{|c|c|c|c|c|c|c|c|c|}
\hline Factor & & & & & & & & Path \\
\hline SCM & $\mathrm{m}$ & $\mathrm{n}$ & S.D & $\begin{array}{l}\text { LOaum } \\
\mathrm{g}^{\mathrm{a}}\end{array}$ & $\mathrm{Alph}^{\mathrm{b}}$ & $\mathrm{CR}^{\mathrm{c}}$ & $A V E^{d}$ & \\
\hline \multirow{3}{*}{ Strategic supplier partnership } & & 3.89 & 1.08 & & 0.827 & 0.877 & 0.589 & \\
\hline & SP1 & & 7 & 0.7059 & 4 & 2 & 5 & 8.5209 \\
\hline & & 3.60 & 1.15 & & & & & \\
\hline \multirow{14}{*}{ Customer service level } & SP2 & & 2 & 0.7637 & & & & \\
\hline & & 3.67 & 1.06 & & & & & \\
\hline & SP3 & & 8 & 0.8629 & & & & \\
\hline & SP4 & 3.62 & .995 & 0.7841 & & & & \\
\hline & SP5 & 3.63 & .993 & 0.712 & & & & \\
\hline & CS & 3.84 & 1.11 & & 0.904 & 0.929 & 0.725 & \\
\hline & 1 & & 8 & 0.7823 & 7 & 4 & 3 & 12.4931 \\
\hline & CS & 3.73 & .902 & & & & & \\
\hline & 2 & & & 0.8502 & & & & \\
\hline & CS & 3.84 & 1.06 & & & & & \\
\hline & 3 & & 7 & 0.8275 & & & & \\
\hline & $\mathrm{CS}$ & 3.89 & 1.08 & & & & & \\
\hline & 4 & & 7 & 0.9163 & & & & \\
\hline & $\mathrm{CS}$ & 3.81 & .938 & 0.876 & & & & \\
\hline
\end{tabular}




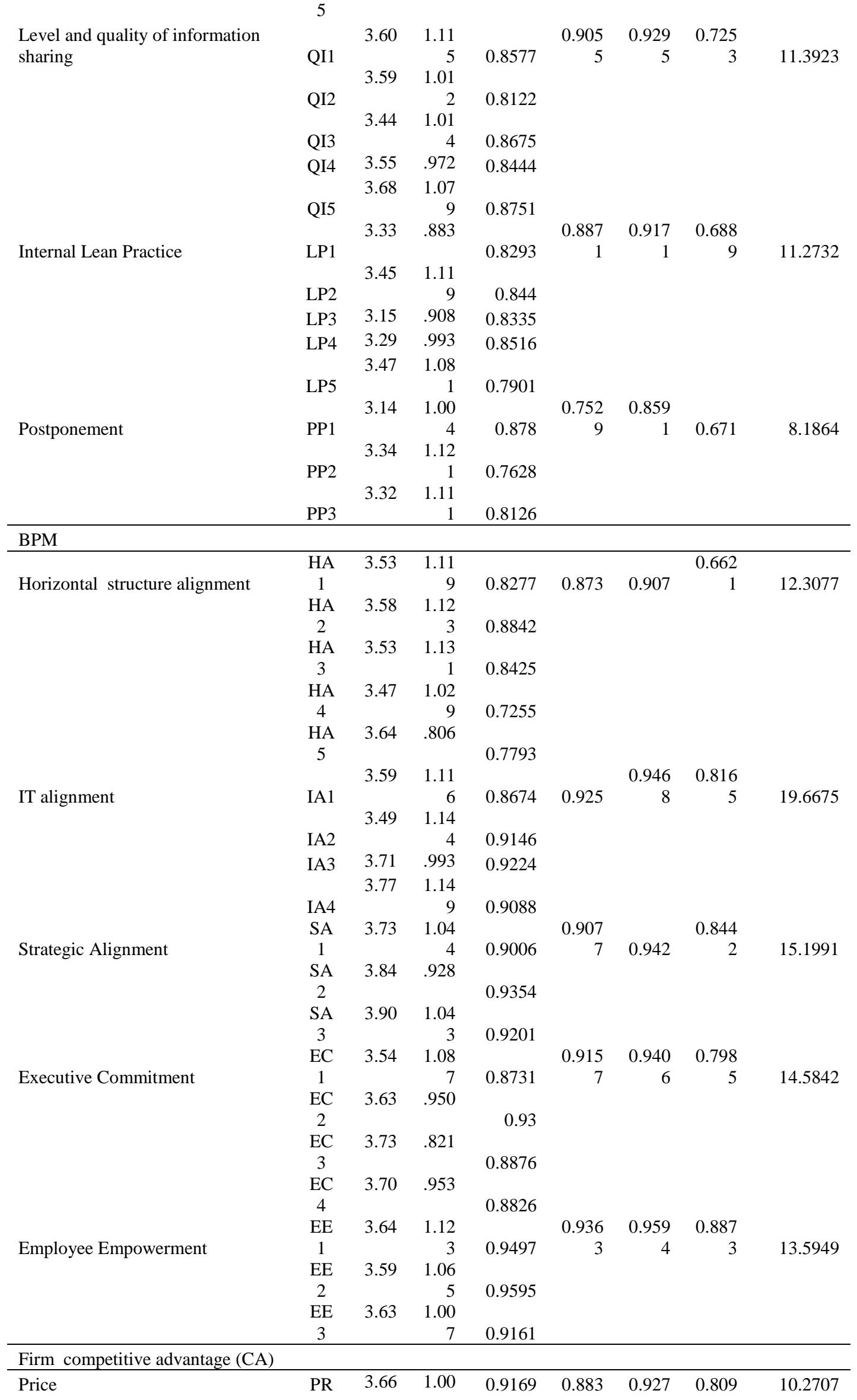




\begin{tabular}{|c|c|c|c|c|c|c|c|c|}
\hline & 1 & & 3 & & 1 & 4 & 8 & \\
\hline & PR & 3.51 & .959 & & & & & \\
\hline & 2 & & & 0.8736 & & & & \\
\hline & PR & 3.63 & .993 & & & & & \\
\hline & 3 & & & 0.9086 & & & & \\
\hline & QL & 3.92 & .983 & & 0.921 & 0.950 & 0.864 & \\
\hline Quality & 1 & & & 0.9288 & 4 & 2 & 1 & 14.5113 \\
\hline & QL & 3.75 & 1.02 & & & & & \\
\hline & 2 & & 4 & 0.9395 & & & & \\
\hline & QL & 3.75 & .997 & & & & & \\
\hline & 3 & & & 0.9202 & & & & \\
\hline & DL & 3.78 & .932 & & 0.891 & 0.932 & 0.821 & \\
\hline Delivery & 1 & & & 0.9053 & 2 & 4 & 5 & 1.4000 \\
\hline & DL & 3.74 & .866 & & & & & \\
\hline & 2 & & & 0.9389 & & & & \\
\hline & DL & 3.84 & .850 & & & & & \\
\hline & 3 & & & 0.8738 & & & & \\
\hline & & 3.60 & .939 & & 0.900 & 0.930 & 0.769 & \\
\hline Product Innovation & PI1 & & & 0.8675 & 4 & 4 & 9 & 11.8544 \\
\hline & PI2 & 3.59 & .969 & 0.8342 & & & & \\
\hline & & 3.56 & 1.00 & & & & & \\
\hline & PI3 & & 0 & 0.8869 & & & & \\
\hline & & 3.68 & 1.07 & & & & & \\
\hline & PI4 & & 9 & 0.919 & & & & \\
\hline Organizational performan & & & & & & & & \\
\hline & & 3.60 & 1.02 & & 0.947 & 0.958 & 0.793 & \\
\hline Economic performance & EP1 & & 4 & 0.8193 & 7 & 4 & 6 & 30.7211 \\
\hline & EP2 & 3.59 & .925 & 0.8962 & & & & \\
\hline & & 3.71 & 1.09 & & & & & \\
\hline & EP3 & & 9 & 0.9009 & & & & \\
\hline & EP4 & 3.58 & .985 & 0.9066 & & & & \\
\hline & EP5 & 3.62 & .967 & 0.8951 & & & & \\
\hline & & 3.59 & 1.02 & & & & & \\
\hline & EP6 & & 5 & 0.9233 & & & & \\
\hline & OP & 3.62 & .892 & & 0.930 & 0.945 & 0.742 & \\
\hline Operational performance & 1 & & & 0.8974 & 2 & 2 & 3 & 28.9444 \\
\hline & OP & 3.62 & .844 & & & & & \\
\hline & 2 & & & 0.9123 & & & & \\
\hline & OP & 3.70 & .982 & & & & & \\
\hline & 3 & & & 0.8543 & & & & \\
\hline & OP & 3.77 & .808 & & & & & \\
\hline & 4 & & & 0.8247 & & & & \\
\hline & $\mathrm{OP}$ & 3.59 & .925 & & & & & \\
\hline & 5 & & & 0.8248 & & & & \\
\hline & OP & 3.60 & .924 & & & & & \\
\hline & 6 & & & 0.8519 & & & & \\
\hline *a All items loadings are s & $\mathrm{t} p<$ & & & & & & & \\
\hline 0.001 & & & & & & & & \\
\hline *b Cronbach's alpha value & & & & & & & & \\
\hline$*_{c} \mathrm{CR}=$ composit score & & & & & & & & \\
\hline$* \mathrm{~d}$ AVE $=$ average varian & & & & & & & & \\
\hline
\end{tabular}

\section{Acknowledgement}

This work was supported by the National Research Foundation of Korea Grant funded by the Korean Government (NRF- 2014S1A5A2A01015385).

\section{References}

[1] W.M.A. Afthanorhan, "A comparison of partial least square structural equation modeling (PLS-SEM) and covariance based structural equation modeling (CB-SEM) for confirmatory factor analysis", International Journal of Engineering Science and Innovative Technology, vol. 2, no. 5, (2013), pp. 198205. 
[2] W.M.A. Afthanorhan, "Hierarchical component using reflective - formative measurement model in partial least square structural equation modeling", International Journal of Mathematics and Statistics Innovation, vol. 2, no. 2, (2014), pp. 33 -49.

[3] A. Agus, "Supply chain management, product quality and business performance", International conference on sociality and economic development IPEDR, vol. 10, (2011).

[4] J. C. Anderson and D. W. Gerbing, "Structural equation modeling in practice: A review and recommended two-step approach", Psychological Bulletin, vol. 103, no. 3, (1988), pp. 453-460.

[5] J. S. Armstrong and T. S. Overton, "Estimating non-response bias in mail surveys", Journal of Marketing Research, vol. 4, (1977), pp. 396-402.

[6] L. Carpinetti, T. Buosi, M.C. Gerolamo, "Quality management and improvement: a framework and a business-process reference model. Business Process Management Journal, vol. 9, no. 4, (2003), pp. 543554 .

[7] B.-Y. Chang and B. Park, "The impact of supply chain and business process managements on firm performance: the mediating effect of competitive Advantage: Part 1 Constructing Hypotheses" International Journal of Control and Automation, (2017).

[8] W. W. Chin, "The partial least squares approach to structural equation mod-eling. In G. A. Marcoulides (Ed.)", Modern methods for business research. NM:Lawrence Erlbaum Associates, (1998).

[9] J. Cohen, "Statistical power analysis for the behavioral sciences, 2nd ed.", Hillsdale, NJ: Erlbaum, (1988).

[10] Council of Logistics Management. What it's all about. Oak Brook: CLM, 2000.

[11] D. S. Soper, "Sobel test calculator for significance of mediation: An interactive calculation tool for mediation tests [online]", (2004), Available at http://www.danielsoper.com/statcalc3/calc.aspx?id=31.

[12] L. M. Ellram, "The supplier selection decision in strategic partnerships" Journal of purchasing and materials and management, (1990), pp. 8-14.

[13] C. Forza, "Survey research in operations management: A process-based perspective", International Journal of Operations Production Management, vol. 22, no. 2, (2002), pp. 152-194.

[14] C. Fornell, D. F. Larcker, "Evaluating structural equation models with unobservable variables and measurement error", Journal of Marketing Research, vol. 18, no. 1, (1981), pp. 39-50

[15] J. F. Hair, C. M. Ringle, M. Sarstedt, "PLS-SEM: Indeed a silver bullet", The Journal of Marketing Theory and Practice, vol. 19, no. 2, (2011), pp.139-152.

[16] J. F. Hair, W. C. Black, B. J. Babin, R. E. Anderson, and R. L. Tatham, "Multivariate Data Analysis", $6^{\text {th }}$ ed., Pearson, USA, (1998).

[17] R. Y. Y. Hung, "Business process management as competitive advantage : a review and empirical study", Total Quality Management, vol. 17, no. 1, (2006), pp. $21-40$.

[18] H. Kaynak, and J.L. Hartley, "A replication and extension of quality management into the supply chain', Journal of Operations Management, vol. 26, no. 4, (2008), pp. 468-489.

[19] S. Li, S.S. Rao, B. R. Nathan, T. S. R. Nathan, "Development and validation of measurement instrument for studying supply chain management practices". Journal of operations management, vol. 23, (2005), pp $618-641$.

[20] Li, S., Nathan, B. R., Nathan, T. S. R., Rao, S.S, "The impact of supply chain management practices on competitive advantage and organizational performance", The international journal of management science, vol. 34, (2006), pp.107 - 124.

[21] P. M. Podsakoff, S. B. MacKenzi, J. Y. Lee, N. P. Podsakoff, "Common method biases in behavioral research: A critical review of the literature and recommended remedies", Journal of Applied Psychology, vol. 88, no. 5, (2003), pp. 879-903.

[22] R. Skrinjar, P. Trkman, "Increasing process orientation with business process management: Critical practices", International Journal of Information Management, vol. 33, (2013), pp. 48 - 60.

[23] K. C. Tan, V.R. Kannan, R.B. Handfield, "Supply chain management: supplier performance and firm performance" International journal of purchasing and materials management, vol. 34, (1998), pp. 2-9.

[24] K. C. Tan, "A framework of supply chain management literature", European journal of purchasing and supply management, vol. 7, (2001), pp. 39-48.

[25] P. Trkman, "The critical success factors of business process management", International Journal of Information Management, vol. 30, (2010), pp. 125 - 134.

[26] S. Youn, M. G. M., Yang, P. Hong and K. Park, "Strategic supply chain partnership, environmental supply chain management practices, and performance outcomes: an empirical study of Korean firms", Journal of Cleaner Production, vol. 56, (2013), pp.121 - 130.

[27] M. Zairi, "Business process management: a boundaryless approach to modern competitiveness", Business process management, vol. 3, no. 1, (1997), pp. $64-80$. 
International Journal of Control and Automation

Vol. 10, No. 5 (2017) 